\title{
Effect of the Time of Day of Instruction on Student Learning
}

Muhammad, N. ${ }^{1}$, Sidhu, G. ${ }^{2}$, Srinivasan, S. $^{3}$

${ }^{1,2,3} \mathrm{~W}$ Booth School of Engineering Practice and Technology, McMaster University

Corresponding email: ssriniv@mcmaster.ca

\begin{abstract}
In this work, we analyse the effect of the time of the day of instruction on student learning on a programming course taught to first-year undergraduate engineering students. A total of 174 students were split into three different groups, each with a different class time. All were taught the same material and by the same instructor. It was found that students in the morning and early afternoon groups performed better than those in the late afternoon group. In all three groups, there was evidence of long-term retention of concepts, which is attributed to the intervention-based active learning environment using the principles of constructivism. Specifically, the techniques of reinforcement and feedback help with long term retention and avoidance of learning wrong concepts, aided by immediate corrective feedback.
\end{abstract}

Keywords: Active learning; Constructivism; Instruction Time; Student Learning; Programming. 


\section{INTRODUCTION}

Providing good quality education is becoming a top priority for institutions around the world. Currently, it is estimated that students master only about $20 \%$ of the material taught to them in a traditional lecture setting (Wage et al., 2005). To address this, much research activity has focused on the evolution of the best teaching and learning practices. This has led to the development of several approaches, such as co-operative and small group learning (Hake, 1998; Prince, 2004; Wage et al., 2005); challenge-based learning (Roseli \& Brophy, 2006); undergraduate research-based learning (Author et al., 2020); inquiry-based learning (Farrell et al., 1999; Lewis \& Lewis, 1999); problem-based learning (Capon \& Kuhn, 2004; Centea \& Srinivasan, 2016, 2017; Dochy et al., 2003; Kolb, 2015; Authors, 2020; Authors et al. 2017); and active learning (Beichner, 2007; Burrowes, 2003; Centea \& Srinivasan, 2015, 2019).With this variety of approaches, and compelling evidence for positive outcomes with each of these pedagogical techniques, it is safe to conclude that the choice of an appropriate pedagogical technique depends upon the type of course and the cohort that is taking it.

Apart from the evolution of such pedagogical practices, researchers have also focused on other parameters that affect learning, for example the time of day when the course is taught (Pope, 2016; Wile \& Shouppe, 2011); the age group (May et al., 1993) and circardian rhythms (Cardinali, 2008; Crowley et al. 2007). Hartley and Nicholls (2008) found that students' performance can depend upon the time of day at which the learning and assessment take place. Virostko (1983) investigated student performance in mathematics for almost two years and concluded that nearly $98 \%$ of the students performed better if the material was taught at the time of the day that was optimal for them individually. This view was also supported by Johnston (2009), who argued that time could be used as an influential parameter to affect learning by using the preferred time of the day for instruction to promote better learning. Lynch (1981) claimed that offering courses at an optimal time of day could help address attendance issues, while Pope (2016) investigated the learning tendencies of around 2 million students and found that they learnt more in the morning than in the afternoon. Specifically, with respect to mathematics, he states that

"A morning math class increases state test scores by an amount equivalent to increasing teacher quality by one-fourth standard deviation."

Millar et al. (1980) claimed that morning learning helped with short-term memory, whereas afternoon learning was better suited to long-term retention. This is echoed in teachers' staff room discussions, where there is general consensus that teaching afternoon classes is more challenging (Sjosten-Bell, 2005). This is because the left hemisphere of our brain dominates in the morning, because of which we have enhanced data processing and better short-term memory at that time (Davis, 1987a). On the other hand, the right hemisphere dominates in the afternoon, allowing for visual processing and better long-term memory. Sjosten-Bell's (2005) assessment of students using quizzes showed that they performed better when these were done in the morning rather than in the afternoon. 
On the other hand, some researchers have found quite the opposite for certain subjects. For instance, in courses involving reading activities, the performance of students has been found to be better in the afternoon than in the morning (Klein, 2004). In 2001, Klein examined the mathematics aptitude and attention spans of students in grades 5 and 10 . He found that with the younger students, more attention was paid during the afternoon, and the least in the morning. Carrell et al. (2011) used a random assignment of college classes and found that if tests were administered an hour earlier, the GPA of the students fell by 0.031 to 0.076 standard deviations. Dills and Hernandez-Julian (2008) made a similar observation, that students performed better when classes started later. In an independent investigation, Edwards (2012) reached a similar conclusion, that starting instruction later improved student performance by $2 \%$. A common conclusion is that with later start times, students are less sleep deprived, implying that sleep deprivation will result in lower performance (Philibert, 2005). However, it must be cautioned that some authors have interpreted this later start time to mean that learning is enhanced in the afternoon rather than in the morning (Carrell et al., 2011; Dills and Hernandez-Julian, 2008).

These trends in learning can be explained using circadian rhythms, which comprise a 24-hour cycle of biochemical, physiological and behavioural processes. These rhythm can impact the storage, as well as the retrieval of information from our brains (Davis, 1987a). In addition, as proposed by Klein (2001), they impact the cardiac function and body temperature. Specifically, the basal arousal level, which is a measure of mental alertness, is directly related to body temperature. Both begin to increase when we wake up and continue to do so throughout the day, with the exception of a dip around noon. High arousal helps with long-term memory (Davis, 1987a; Millar et al.., 1980). Goldstein et al. (2007) found a six-point difference in IQ equivalents between the arousal time of a person and the time of testing. Literature on circadian rhythms shows that activity levels in adolescents are higher in the afternoon than in the morning (Crowley et al., 2007). However, the effect of the time of day on the performance varies considerably across studies; in fact, a general conclusion that one can draw from the literature is that the best time of day to perform a particular task and achieve optimal results depends upon the task.

In this work, we analyse empirical data on students taking a programming course in the first year of an undergraduate engineering programme, and attempt to determine the optimal learning schedule that will produce the best outcomes for the students. The students were distributed into three different groups that were taught at different times of the day. For the teaching and learning approach, we used active learning techniques grounded in the principles of constructivism (Honebein, 1996; Oliver, 2000). The overall objective of the study is to understand the impact of the time of day of instruction on the engagement of students in their learning. Learning in this case is measured by the performance of the students in their midterm and final exams.

The remainder of the paper is organised as follows. In Section 2 we describe the materials and methods used in this study, followed by the Results section, in which we describe the data collected from the study. A discussion on these data is presented in Section 4, with the conclusions presented in Section 5. 


\section{MATERIALS AND METHODS}

\section{Course Design}

The course on which the analysis centres was an advanced course in the C++ programming language. More precisely, the course was focused on teaching advanced concepts of object-oriented programming. The students taking the course were enrolled on a 4-year undergraduate engineering technology programme, with specialisation in the areas of automotive and vehicle technology, and automation engineering technology. The specific topics taught on the course included pointers, abstract data types, classes and objects, overloading functions and constructors, inheritance, polymorphism, abstract classes, and UML diagrams.

The course was offered over a duration of 12 weeks. Three groups, each with a different class time, were available for the students to enrol in. Group 1 started at $9.30 \mathrm{am}$, Group 2 at $12.30 \mathrm{pm}$, and Group 3 at $4.30 \mathrm{pm}$. A total of 174 students were enrolled into these groups by the registrar's office, based on their timetables and other courses that they had to take in the term. As a result, Group 1 comprised 59 students, Group 2 consisted of 61, and Group 3 of 54. All three groups were taught by the same instructor, and the content was delivered in an identical manner.

\section{Procedure}

The course was delivered for a duration of 12 weeks. Each week, the class met twice, each time for two hours. In all three groups, the first class was used to deliver the concepts, to illustrate examples using these, and to allow students to solve problems on their own. The class took place in a computer lab setting, where all the instruction and interaction with the students was characterised by computer-aided interaction; i.e., live coding by the instructor and students.

The second two-hour class each week was lab work, in which students had to solve two or three programming questions in which they had to apply the concepts learned in the previous lectures. Students were allowed to interact with their peers as well as with the instructor. The second class was at the same time of day as the first one for each group. The students had to submit solutions to the programming assignments for grading. The deadline for submissions was always set at midnight on the Sunday the week the lab questions had been assigned. This gave students time to continue working on the problems outside of class. They also they had to sit a midterm and a comprehensive final exam.

Apart from the labs and the exams, the students had to work on a project that was larger in scope. This three-week project was another mode of assessing the ability of the students to apply the concepts, thus illustrating the higher levels of Bloom's taxonomy (Bloom, 1984). The project was a more intense format of lab work, with students given three weeks to conceive and solve a fairly complex problem by employing several principles of the object-oriented programming taught in class. The complexity of the problem proposed by the students required approval from the instructor. Furthermore, to ensure that minimum standards were maintained, a set of guidelines was posted for the students that outlined the minimum features/aspects required on the final programme. During the implementation of the 
project, students were required to report interim progress at various stages, and the instructor was actively involved in advising the students on successful implementation of the project. These interim-stage discussions enabled the instructor to gauge the level of understanding of the students and to introduce interventions in the form of additional examples in the classroom.

The midterm exam evaluated the students' logic building abilities and understanding of the various concepts via simple programming problems. Specifically, the exam questions focused on the students' ability to remember, understand and apply particular concepts to engineering problems, thereby engaging with the lower levels of Bloom's taxonomy. The final exam evaluated the students' abilities to solve more challenging problems by analysing, evaluating and creating solutions to problems, thereby reaching the higher levels of Bloom's taxonomy. The midterm and final exams were 2 and 2.5 hours in length respectively, and formed a significant basis for measuring the students' understanding and mastery of the concepts.

\section{Active Learning}

Active learning was an integral part of the course for all three groups. To stimulate an active learning ecosystem, live code debugging exercises were undertaken in the classroom, in which the students would participate together with the instructor in developing the code for a simple problem that introduced the concepts to them. The learning experience was enriched by encouraging student discussions on alternative approaches to implement the program logic. This not only enabled engagement of the students in an environment in which they could experience various possibilities of solving the same problem, but also allowed the instructor to gauge their understanding of the concepts and to calibrate the lecture accordingly.

\section{Data Collection}

A variety of approaches were used to collect data to measure student learning. The more informal approaches included classroom discussions between the students and the instructor during the problem-solving sessions to determine the level of understanding of the concepts. More formal assessment included the evaluation of the assignments that the students handed in as part of their submissions for the lab work. This enabled the instructor to determine the level of understanding and to adjust accordingly the pace of the course, either by introducing more sample problems or encouraging additional discussions to elucidate some of the points that the students were missing in the solutions.

Similarly, the project undertaken by the students was another mode of assessing their ability to apply the concepts and thus demonstrate the higher levels of Bloom's taxonomy (Bloom, 1984). The project was a more intense format of lab work, for which the students were given three weeks to conceive and solve a fairly complex problem that employs several principles of object oriented programming taught in the class. The complexity of the problem proposed by the students requires an approval from the instructor. Further, to ensure that a minimum standard is maintained, a set of guidelines are posted for the students to follow. During the course of implementation of the project, students are required to report the interim 
progress at various stages, and the instructor is actively involved in advising the students for a successful implementation of the project. These interim stage discussions enable the instructor to gauge the level of understanding of the students, and introduce interventions in the form of additional examples in the classroom.

More rigorous assessments to evaluate student understanding of the concepts were made via midterm and final exams. The midterm exam was weighted at $26 \%$ of the overall course grade and lasted 2 hours, while the final exam contributed $35 \%$ of the overall course grade. While the midterm one was computer-based, the final exam was paper-based and closed book. The quantitative data from these two assessments were used in the study to evaluate the influence of the class schedule on the performance of the students.

\section{RESULTS}

The overall performance of the students in the midterm and final exams is shown in Figure 1 for all three groups. As seen in the figure, the performance of the students in Groups 1 and 2 are much better than that of the students in Group 3 in both exams. More precisely, the average scores of Groups 1 and 2 were almost 64\%, whereas Group 3 had a much poorer performance, averaging around $54 \%$. In the final exam, the difference between the first two groups was more pronounced. While Group 1 performed reasonably well, with an average score of 70\%, Group 2 performed the best, with an average score of $73 \%$. As in the midterm exam, Group 3 displayed the worst performance, with an average of $65 \%$. Clearly, in the evening class (Group 3) starting at 4.30pm, student performance was around 8-10\% lower with respect to Group 2, which had the best performance.

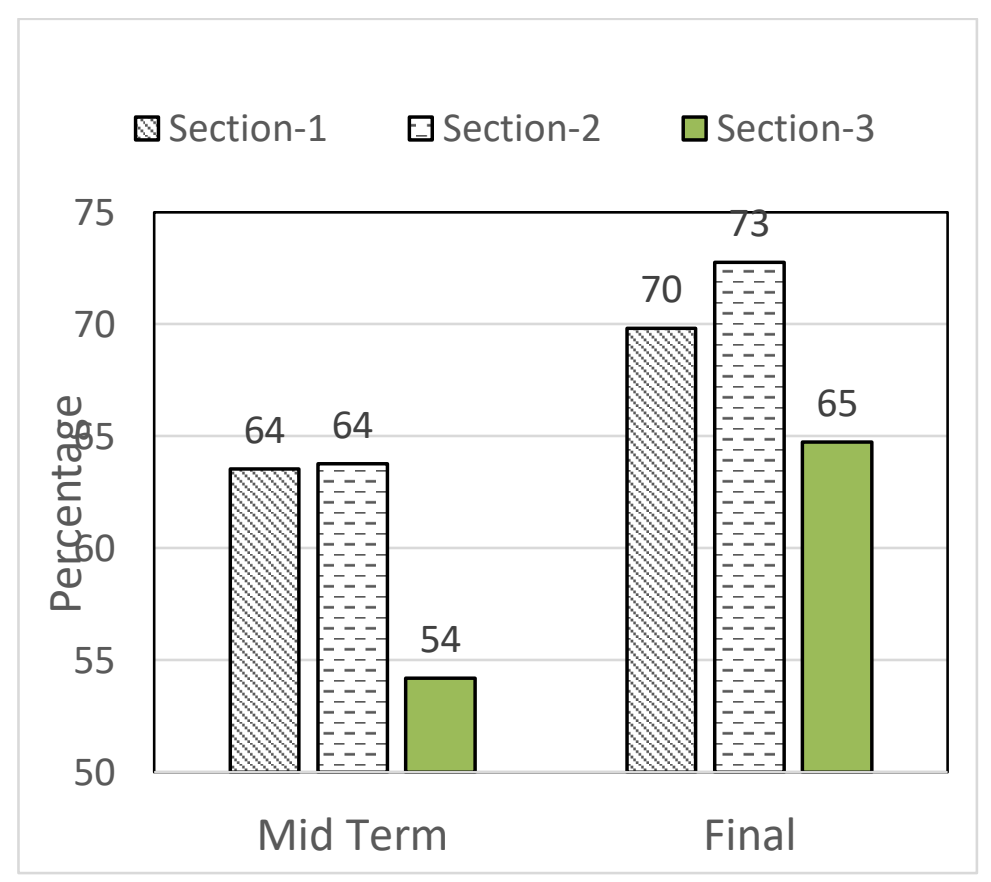

Fig. 1: Average scores of the three groups in the midterm and final exams. Group 1 started class at 9.30am, Group 2 at $12.30 \mathrm{pm}$ and Group 3 starts at $4.30 \mathrm{pm}$. 
An interesting observation is that the performance of the students in all three groups improved from the midterm to the final exam. More precisely, in Group 1 this improvement was around 6\%, whereas in Group 2 the average scores improved by about $9 \%$. Group 3 had the greatest improvement, at $11 \%$. This can be attributed to the combination of the instruction time of the class (Pope, 2016), the intervention strategies (Authors, 2018), and favourable circardian rhythms (Crowley et al., 2007).

More in-depth understanding of these averages can be obtained from the distribution of grades in the midterm and final exams, which are shown in Figures 2 and 3 respectively.

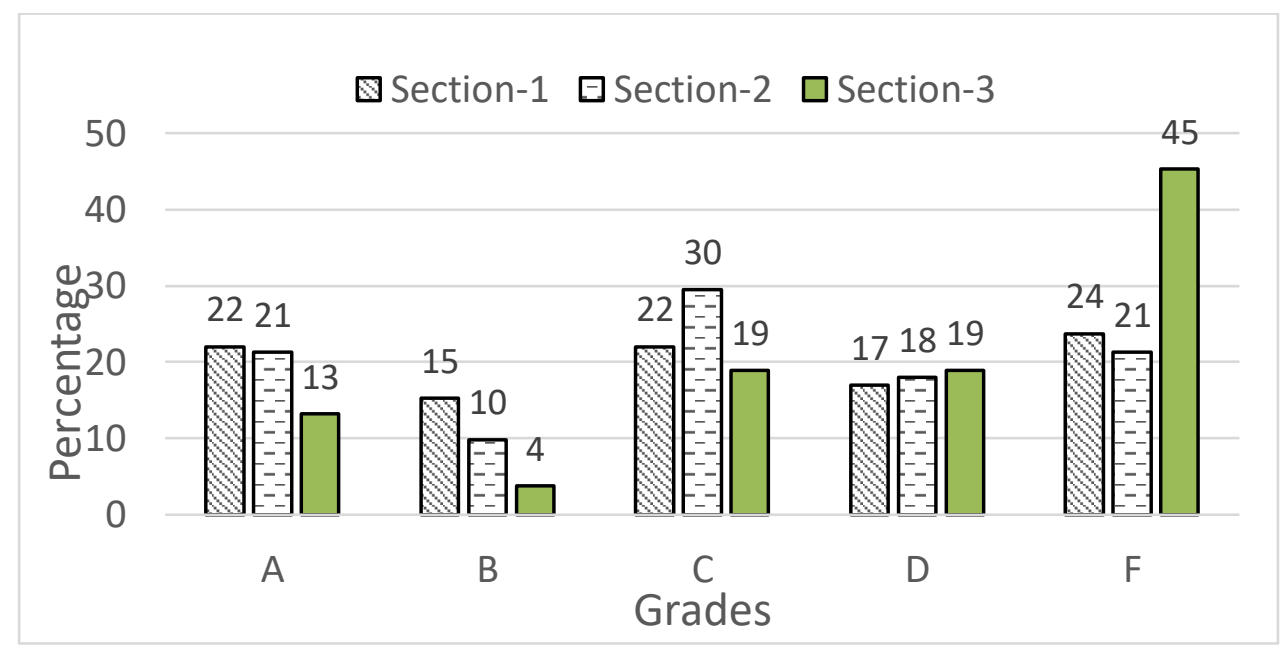

Fig. 2: Grade distribution in the midterm exam.

As seen in Figure 2, the performance of Groups 1 and 2 was nearly the same in all the letter grades. More precisely, around $60 \%$ of the students in the first two groups had scores within the first three grades. On the other hand, students in Group 3 underperformed, with almost double the number of failing students in the midterm exam than in Groups 1 or 2 . Furthermore, nearly $38 \%$ of the passing students in this group achieved grades of $\mathrm{C}$ or $\mathrm{D}$.

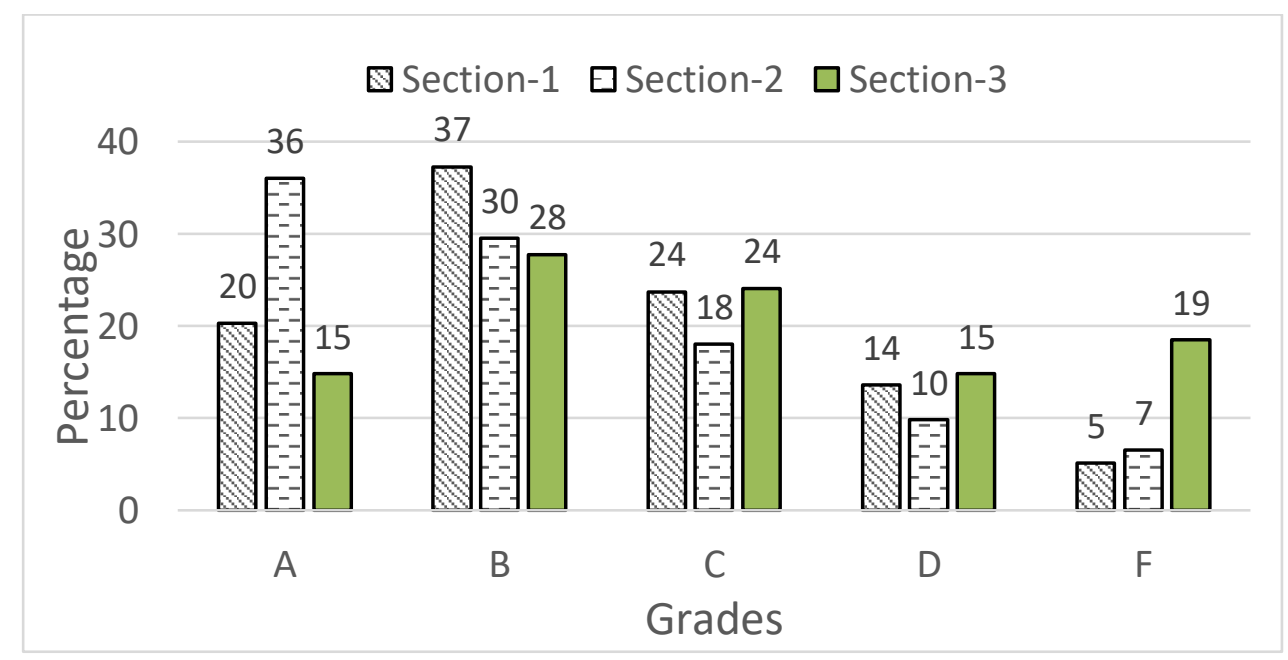

Fig. 3: Grade distribution in the final exam. 
The performance of the students in all three groups changed in the final exam; this improved performance is summarised in Figure 3. As seen in the figure, for Group 1 there was a significant increase in the number students scoring grade B, while there was a significant fall in the number of failures. In Group 2, the best performing group, there was a steep rise in the number students achieving grades $\mathrm{A}$ and $\mathrm{B}$, and a marked decline in the number of failing students. In Group 3, there was fairly uniform distribution of grades, with a slight peak for grade B. Nevertheless, this group still saw a significant percentage of students failing the course compared to Groups 1 and 2.

\section{DISCUSSION}

From the results described in the previous section, two main conclusions can be drawn: (a) student learning, as measured by the assessments, is better in the morning (Group 1) and early afternoon (Group 2) than in the late afternoon/early evening (Group 3); and (b) across all three groups, there is evidence of learning, and more importantly, that this learning improves over time. This is clearly seen from the better performance of the students during the final exam. In the following paragraphs we discuss these two major outcomes.

The performance of the three groups, as summarised in Figure 1, was expected and is in agreement with the trends in the literature. More precisely, morning learning is beneficial for the short-term recall of concepts, as found by Millar et al. (1980). This is because the left hemisphere of the brain generally dominates in the morning, which aids short-term memory performance (Davis, 1987a). Furthermore, logical reasoning, analytical thinking, linear reasoning, numerical manipulation and mathematical concepts, all of which are activities related to the course, correspond to the left hemisphere functions (Klein, 2001; Wile and Shouppe, 2011). On the other hand, early afternoon learning aids long-term retention of concepts (Klein, 2001). In fact, since the course required both short-term and long-term memory (Davis 1987b), Group 1 was positioned to derive the benefits of both types of retention. The timing of Group 2 was ideally suited to the long-term retention of concepts as the classes were held in the early afternoon. Coupled with the manner in which the course was conducted, this was conducive to learning.

In all three course groups, learning can be attributed to the way the course was conducted. More precisely, in delivering the concepts to the students, it embedded the principles of behaviourism and constructivism, the latter being more predominant. The course was taught using the same principles in all three groups.

The principles of behaviourism were applied to clearly define the timetable of topics, the precise activities to be undertaken inside and outside the class, the durations of activities, and the associated assessments. All of these were put into the context of the expected learning outcomes, the duties of the students, and the role of the instructor in creating a conducive learning environment. This helped introduce a structure into the delivery of the material, and aided the cohort to be productive and to successfully meet all the learning outcomes in a timely manner. Once this was done, the classroom changed to an active learning environment, in which students were engaged with the instructors and their peers to solve 
programming examples that elucidated the various concepts. In such an environment, the three main tasks that the students undertook while developing programs for the questions were: (i) to infer information pertaining to the logic that was not explicitly stated in the question; (ii) to apply the acquired concepts to successfully implement the program; and (iii) to evaluate the solution by running a variety of test cases.

The main contributor to the learning was the employment of constructivist principles inside the classroom. In this approach, the interventions embedded in the course were such that the students were routinely required to recall the concepts and apply them to solve a variety of problems. This was done in collaboration with the instructor as well as their peers, which gave students a chance to develop a mental construction of the concepts. To observe the applicability of the concepts, the students were asked to apply them to solve a variety of problems, fostering a sound understanding of them. By engaging in a multitude of such activities, the students were able to cement the concepts in their minds.

In these active learning sessions, to reinforce the concepts the classroom activities were focused on routine recall and application of the concepts recently taught to a variety of problems. This enabled us to entrench them in the students for long-term retention. In addition to the time of day when the course was taught, this reinforcement strategy employed with all three groups resulted in significant improvement in the performance of the students in the final exam. This is clearly evident in Figure 2, which shows that the students in all three groups were able to demonstrate notable improvement to their long-term retention. Another important aspect that enhanced learning was the instantaneous feedback that the students received while solving the problems in the class. While these interactions helped create a good mental construction of the concepts, enriching their learning experience, it also gave the instructors and teaching assistants an opportunity to correct any misunderstanding of them. Therefore, the reinforcement of the concepts, combined with the instant feedback, enabled avoidance of the retention of wrong concepts.

\section{CONCLUSION}

In this work, we have investigated the effect of the time of day at which instruction took place on students' learning. The experiment was conducted on a first-year undergraduate engineering programming course. A total of 174 students were enrolled in three groups by the registrar's office based on their timetables and in line with other courses they had to take in the term. Group 1 started at 9.30am, Group 2 at $12.30 \mathrm{pm}$ and Group 3 at $4.30 \mathrm{pm}$. All groups were taught by the same instructor, and the content covered was identical. The students were taught in an active learning environment, using principles of constructivism. Learning was measured by the student performance in the lab, in a project, and in midterm and final exams. The key findings are follows:

(a) Student learning was better in the morning and early afternoon groups compared to the late afternoon group. This can be attributed to the fact that the course required a significant amount of logical reasoning, linear 
reasoning, and mathematical skills, all of which are associated with functions of the left-hand side of the brain, which is dominant during the morning. This is consistent with the observations made in the literature about courses that require such skills.

(b) Across all three groups, the performance of the students improved from the midterm exam to the final exam. This can be attributed to the active learning-based intervention strategy that was used with the three groups, involving reinforcement and instant feedback techniques. While the former aids in long-term retention of concepts, the latter helps students minimise the learning of wrong concepts, that without immediate corrective measures could be difficult to erase from the mind.

\section{REFERENCES}

Beichner, R. (2007). The Student-Centered Activities for Large Enrollment Undergraduate Programs (SCALE-UP) Project.

Bloom, B. S. (1984). The 2-Sigma Problem: The Search for Methods of Group Instruction as Effective as One-to-One Tutoring. Educational Researcher, 13, 4-16.

Burrowes, P.A. (2003).A Student-Centered Approach to Teaching General Biology That Really Works: Lord's Constructivist Model Put to a Test. Am. Biol. Teach. 65, 491-502.

Capon, N. \& Kuhn, D. (2004). What's So Good About Problem-Based Learning?, Cogn. Instr. 22, 61-79.

Cardinali, D. (2008). Chronoeducation: How the Biological Clock Influences the Learning Process. In: A. M. Battro, K. W. Fischer, \& P. J. Léna (Eds.), The Educated Brain Cambridge: Cambridge University Press.

Carrell, S. E., Maghakian, T., \& West, J., (2011). A's from Zzzz's? The Causal Effect of School Start Time on the Academic Achievement of Adolescents. American Economic Journal: Economic Policy, 3, 62-81.

Centea, D. \& Srinivasan, S. (2016). Assessment Methodology in a PBL Environment. International Journal of Innovation and Research in Educational Sciences, 6(6), 364-372.

Centea, D. \& Srinivasan, S. (2017). Enhancing Student Learning through Problem Based Learning. In: A. Guerra, F. J. Rodriguez, A. Kolmos, \& I.P. Reyes (Eds.), PBL, Social Progress and Sustainability. (pp. 376-385). Aalborg: Aalborg Universitetsforlag. (International Research Symposium on PBL)..

Crowley, S., Acebo, C., \& Carskadon, M. (2007). Sleep, Circadian Rhythms, and Delayed Phase in Adolescents. Sleep Medicine, 8, 602-612.

Cummings, K., Marx, J., Ronald, T., \& Dennis, K. (1999). Evaluating innovation in studio physics, Am. J. Phys. 67, S38-S44

Davis, Z. (1987a). Effects of time-of-day of instruction on beginning reading achievement. Journal of Educational Research, 80(3), 138-140.

Davis, Z. (1987b). The effects of time-ofday of instruction on eighth grade students' English and mathematics achievement. The High School Journal, 72(2), 78-80.

Dills, A. K., \& Hernandez-Julian, R. (2008). Course Scheduling and Academic Performance. Economics of Education Review, 27, 646-654.

Dochy, F., Segers, M., Van den Bossche, P., \& Gijbels, D. (2003) Effects of problem-based learning: a meta-analysis. Learn. Instr., 13, 533-568.

Edwards, F. (2012). Early to Rise? The Effect of Daily Start Times on Academic Performance. Economics of Education Review, 31, 970-983.

Farrell, J.J., Moog, R.S., \& Spencer, J.N. (1999). A Guided-Inquiry General Chemistry Course. J. Chem. Educ. 76, 570.

Goldstein, D., Hahn, C., Hasher, L., Wiprzycka, U., \& Zelazo, P. (2007). Time of day, intellectual performance, and behavioral problems in morning versus evening type adolescents: Is there a synchrony effect? Personality and Individual Differences, 42(3), 431. 
Hake, R.R. (1998). Interactive-engagement versus traditional methods: A six-thousand-student survey of mechanics test data for introductory physics courses. Am. J. Phys. 66, 64-74.

Hartley, J., \& Nicholls, L. (2008). Time of day, exam performance and new technology. British Journal of Educational Technology, 39(3), 555-558.

Honebein, P. C. (1996). Seven goals for the design of constructivist learning environments. Constructivist learning environments: Case studies in instructional design, 11-24.

Johnston, H. (2009). Research brief learning time and student achievement. Education Partnerships, Inc..

Klein, J. (2001). Attention, scholastic achievement and timing of lessons. Scandinavian Journal of Educational Research. 45(3), 301-309.

Klein, J. (2004). Planning middle school schedules for improved attention and achievement. Scandinavian Journal of Educational Research. 48(4), 441-450.

Kolb, D.A. (2015). Experiential Learning: Experience as the Source of Learning and Development, 2nd ed. Pearson Education Inc.

Lewis, S.E. \& Lewis, J.E. (2005). Departing from Lectures: An Evaluation of a Peer-Led Guided Inquiry Alternative. J. Chem. Educ. 82, 135.

Lynch, P. K. (1981). An analysis of the relationships among academic achievement, attendance, and the learning style time preferences of eleventh and twelfth grade students identified as initial or chronic truants in a suburban New York school district (St. Johns University, New York), (Doctoral Dissertation).

May, C. P., Hasher, L., \& Stoltzfus, E. R. (1993). Optimal time of day and the magnitude of age differences in memory. Psychological Science, 4(5), 326-330.

Millar, K., Styles, B., \& Wastell, D. (1980). Time of day and retrieval from longterm memory. British Journal of Psychology, 71, 407-414.

Muhammad, N. \& Srinivasan, S. (2020). A Problem Solving Based Approach to Learn Engineering Mathematics. In: M. Auer, H. Hortsch, \& P. Sethakul (Eds), The Impact of the 4th Industrial Revolution on Engineering Education. ICL 2019. Advances in Intelligent Systems and Computing, 1134, 839-848.

Oliver, K. M. (2000). Methods for developing constructivism learning on the web. Educational Technology, 40(6)

Philibert, I. (2005). Sleep Loss and Performance in Residents and Nonphysicians: A Meta-Analytic Examination. Sleep, 28, 1392-1402.

Pope, N. G. (2016). How the time of day affects productivity:Evidence from school schedules. The Review of Economics and Statistics, 98(1), 1-11.

Prince, M. (2004). Does Active Learning Work? A Review of the Research. J. Eng. Educ. 93, 223231.

Roselli, R.J. \& Brophy, S.P. (2006). Effectiveness of Challenge-Based Instruction in Biomechanics. J. Eng. Educ. 95, 311-324.

Sidhu, G. \& Srinivasan, S. (2018) An Intervention-Based Active-Learning Strategy To Enhance Student Performance in Mathematics. Int. J. Pedagog. Teach. Educ. 2, 277-288.

Sidhu, G., Srinivasan, S., \& Centea, D. (2017). Implementation of a Problem Based Learning Environment for First Year Engineering Mathematics In: A. Guerra, F. J. Rodriguez, A. Kolmos, \& I. P. Reyes (Eds), PBL, Social Progress and Sustainability. (pp. 201-208). Aalborg: Aalborg Universitetsforlag. (International Research Symposium on PBL)..

Sjosten-Bell, W. (2005). Influence of timeof- day on student performance on mathematical algorithms. 1-52. doi: ED490712

Srinivasan S. \& Centea D. (2019). An Active Learning Strategy for Programming Courses. In: M. Auer \& T. Tsiatsos (Eds). Mobile Technologies and Applications for the Internet of Things. IMCL 2018.. Advances in Intelligent Systems and Computing. 909, 327-336.

Srinivasan S., Rajabzadeh A.R., \& Centea D. (2020). A Project-Centric Learning Strategy in Biotechnology. In: M. Auer, H. Hortsch , \& P. Sethakul P. (Eds) The Impact of the 4th Industrial Revolution on Engineering Education. ICL 2019. Advances in Intelligent Systems and Computing, 1134, pp 830-838. Springer, Cham.

Srinivasan, S. \& Centea, D. (2015). Applicability of Principles of Cognitive Science in Active Learning Pedagogies, Proceedings of the 13th International Workshop Active Learning in Engineering. (1st ed.) Aalborg Universitetsforlagpp, 99-104. 
Virostko, J. (1983). An analysis of the relationships among academic achievement in mathematics and reading, assigned instructional schedules, and the learning style time preferences of third, fourth, fifth, and sixth grade students (St. Johns University, New York), (Doctoral Dissertation)

Wage, K.E., Buck, J.R., Wright, C.H.G., \& Welch, T. B. (2005). The signals and systems concept inventory. IEEE Trans. Educ. 48, 448-461

Wile, A. J. \& Shouppe, G. A. (2011). Does Time-of-Day of Instruction Impact Class Achievement? Perspectives in Learning: A Journal of the College of Education \& Health Professions, 12(1), 21-25. 